\title{
A Clinical Evaluation of an Electric Toothbrush
}

\author{
BY WILLIAM A. SMITH, D.D.s., M.s., SAN ANTONIO, TEXAS, AND \\ MAJOR M. ASH, JR.," D.D.s., M.s., ANN ARBOR, MICHIGAN
}

$\mathrm{A}^{\mathrm{N}}$

NUMBER of clinical ${ }^{1,2,3,4}$ and nonclinical $^{5,6,7}$ investigations, including safety ${ }^{7}$ and abrasion studies, ${ }^{5,6}$ have been conducted to evaluate electric toothbrushes. The prevention or removal of dental plaque, removal of oral debris, trauma to soft tissue, effect on gingivitis and stippling, bleeding on instrumentation, and the effect on keratinization have all been used as a means of assessing the effectiveness of the electric toothbrush in clinical studies. One or more of such methods of assessment of electric brushes have been used in studies conducted on hospitalized patients, ${ }^{8}$ handicapped children ${ }^{9}$ and adults, ${ }^{2}$ mentally retarded children, ${ }^{10}$ normal children, ${ }^{11,12}$ periodontal patients, ${ }^{13,14}$ dental students and/or hygienists, ${ }^{1,3,11,15,16,17,18,19}$ edentulous patients, ${ }^{20}$ and "nondentally oriented" college students. ${ }^{4}$ Although these studies have provided valuable information, there appears to be no general agreement that any electric toothbrush is any more or less effective than the regular hand brush. Furthermore, no detailed assessment of the effect on periodontal disease, as represented by a comprehensive periodontal disease index, has been undertaken in any investigation. The purpose of this study was: (1) to compare the effectiveness of an electric toothbrush* and a regular hand brush in

*Broxodent toothbrush, distributed by the E. R. Squibb \& Sons Co.

preventing or removing dental plaque, and (2) to compare their effect on the gingiva and periodontium as indicated by gingivitis and periodontal indices.

\section{MATERIALS AND METHODS}

In order determine the effect of both brushes under conditions where patients ex-

\footnotetext{
*Professor of Periodontics at the School of Dentistry, The University of Michigan.
}

hibited a broad range of periodontal status, adult subjects with varying degrees of cemental exposure, loss of interproximal tissue, and a wide range in age were selected. An even distribution of sex also was desired and given consideration in forming comparable groups. It also was desirable to select patients in which all periodontal therapy and reconstruction had been completed, in order that such procedures would not interfere with the scoring of the various criteria used during the period of the study. On the basis of these considerations, 82 subjects were selected from the dental clinic of The University of Michigan School of Dentistry. The selected subjects were formed into two comparable groups as explained under formation of groups.

Six teeth have been suggested by Ramfjord $^{21}$ to be representative of all the teeth in regards to plaque, gingivitis, and periodontal scores. Studies by Shick and $\mathrm{Ash}^{22}$ and Jamison ${ }^{23}$ have shown these teeth to be a valid presentation for the plaque, gingivitis, and periodontal scores of all teeth present in the mouth. "Scores of P.D.I. for the upper right first molar, left central incisor, left first premolar, lower left first molar, right central incisor, and right first premolar approximate the scores of P.D.I. for all of the teeth." 23 Because of proved reliability ${ }^{22,23}$ and accurate assessment of periodontal disease, ${ }^{24}$ the scoring indices of Ramfjord ${ }^{21}$ and those of Shick and $\mathrm{Ash}^{22}$ were used in this study. Thus, plaque scores were evaluated using the method of Shick and $\mathrm{Ash},{ }^{22}$ and gingivitis and periodontal scores were evaluated by a modification of Ramfjord's index. ${ }^{21}$ Instead of using one score to designate the gingivitis present around each tooth, the facial and lingual surfaces were considered as separate entities; each surface received its own score. Similarly, Ramfjord's criterion ${ }^{21}$ for the periodontal score was modified so that each fa- 
cial and lingual surface received a separate score.

\section{OUTLINE OF EXPERIMENTAL PROCEDURES}

Since the plan for this investigation was to evaluate the Broxodent electric toothbrush by comparing it with a standard design hand toothbrush, comparable groups which were to use the two brushes were formed on the basis of age, sex, initial plaque score, gingivitis, and periodontal scores. Rate of plaque formation and changes in gingivitis and periodontal scores after a prophylaxis were criteria also used for grouping patients. The two groups which were formed using such criteria were comparable statistically at the one per cent level of confidence.

After initial scores were obtained, all patients in each group received a complete prophylaxis and were subsequently scored at 30 and 60 days. During this initial 60 day period one group used the Broxodent and the other group used the standard hand brush. After the 60 day scoring, all the patients received a complete prophylaxis and the type of brush changed; that is, the group which started on the Broxodent electric toothbrush was switched to the standard design hand brush and the group which started on the hand toothbrush received the Broxodent electric brush. Patients were scored again at 90 and 120 days.

At each scoring period of the study, plaque, gingivitis, and periodontal scores were determined for all patients. The numbers of the six teeth used in the scoring were: tooth \#3, the maxillary right first molar; tooth \#9, the maxillary left central incisor; tooth \#12, the maxillary left first bicuspid; tooth \#19, the mandibular left first molar; tooth \#25, the mandibular right central incisor; and tooth \#28, the mandibular first bicuspid.

\section{STANDARDIZATION OF SCORING}

To determine whether or not the examiner could assess the same degree of plaque, gingivitis, and periodontal scores repeat- edly, repeated random scorings were carried out and analyzed for the degree of variation. Thus scoring methods were standardized for reproducibility and reliability. Four patients were selected at random and scored three times at random in the same morning. No patient was scored consecutively. The method of scoring plaque was standardized on two different occasions, while gingivitis and periodontal indices were standardized only once. The first, second, and third scorings of the individual teeth of each subject were compared. Analysis of the reproducibility of the scoring method indicated that the examiner's average deviation for a single plaque score was -0.019 units; the average deviation for gingivitis score was +0.05 units; the average deviation for periodontal score was -0.008 units. These degrees of error are considered to be well within permissible levels.

\section{FORMATION OF GROUPS}

To form comparable groups individual scores for the six teeth were added to get a total score for each subject in: (1) initial plaque score, (2) initial gingivitis score, (3) initial periodontal score, (4) rate of plaque formation, (5) change in gingivitis score, and (6) change in periodontal score after complete prophylaxis. Each patient was arranged from 1 to 82 depending on his total score in the above six scorings. One designated the lowest score and 82 designated the highest score found in the 82 patients. Thus each patient had six numbers corresponding to his position in each group. These six numbers were again averaged and arranged in a list from 1 to 82. Number 1 was assigned to Group I, Number 2 was assigned to Group II, and similarly down the list assigning an equal number of males and females to each group. Whenever possible equal numbers of the oldest patients were placed in alternate groups. The two formed groups were comparable at the 0.01 per cent level of confidence for all criteria used.

To obviate the novelty effect of the Broxodent electric toothbrush the brushes 
were switched at the end of 60 days. It was felt that a 30 day period on a toothbrush was sufficient to determine any changes in plaque ${ }^{22}$ and gingivitis scores; however, there was some uncertainty regarding the change which might occur in the periodontal score in 30 days, therefore it was decided that 60 days might be adequate.

During the time period involved in this study, four patients dropped out, two of each group. Statistical re-evaluation revealed the two groups were still statistically comparable, both before and after prophylaxis. These four patients were not included in any of the subsequent statistical data (Table 1).

\section{BRUSHING METHODS}

No specific method of toothbrushing has been accepted as a standard method. Some writers $^{25,26,27,28}$ advocate one method for all patients, while others ${ }^{29,30,31,32,33}$ believe the brushing technique should be carefully adapted to the needs of the individual. Clinical studies ${ }^{22,29}$ have shown Charter's, ${ }^{29}$ vertical, ${ }^{22}$ and roll-method ${ }^{22,29}$ of brushing to be equally effective regarding efficiency and effectiveness in preventing and removing soft accretion on the surfaces of the teeth. The roll-method (sweeping motion) is "rather universally used"26 and often is advocated. ${ }^{26,28,29,33}$ The advocates of the roll-method agree that the "standard design" toothbrush is used effectively and efficiently with this method of brushing. ${ }^{22}$ Thus, the roll-method using the "standard design" toothbrush was selected to be used as a basis of comparison with the electric toothbrush.

\section{TYPES OF BRUSHES}

Two types of brushes were used in this study, a standard design toothbrush and the electric toothbrush.* The standard design toothbrush, the \#12,** has a solid

*The Broxodent ${ }^{\circledR}$ was supplied by the E. R. Squibb \& Sons Co.

**The Lactona \#12 was supplied by the E. R. Squibb \& Sons Co. handle and two rows of six tufts containing hard natural bristles. It was not considered necessary to use a hand brush with similar bristles as the electric brush since it was felt that it would be best to compare the electric brush with a standard design brush having commonly used bristles.

The electric toothbrush has an arcuate action through a sixty degree vertical arc at the rate of sixty oscillations per second. It has interchangeable heads containing rounded end Rilson $(R)$ filaments arranged in three rows. The two outer rows contain five tufts of filaments, while the inner row has four tufts arranged alternately between the tufts of the outer rows.

\section{TOOTHBRUSHING INSTRUCTIONS}

Three minute intra-oral instructions were given each patient after which the patient demonstrated his ability to use the method of brushing.

The roll-method of brushing consists of placing the sides of the bristles against the attached gingiva parallel with the long axis of the tooth. The bristle ends point in an apical direction. Initially, the bristles are pressed against the attached gingiva with sufficient force to blanch the tissues. The wrist is rolled moving the bristle ends slowly across the tooth in a coronal direction. Using this method, the bristles move down on the maxillary teeth and up on the mandibular teeth. The patients were requested to repeat this roll-method four or five times in each area before moving the brush to the adjacent area. Systematic coverage of the entire mouth was stressed.

Similarly, three minute intra-oral instructions were given using the electric brush. When the brush was stopped, the patient was instructed to place the filament ends at a 90 degree angle to the long axis of the tooth with the outer row of filaments at the free gingival margin. After starting, the brush was kept in this plane for the entire quadrant. Instructions included frequent stopping of the brush to insure proper alignment of the filaments. Again, 
Before Prophylaxis

\begin{tabular}{|c|c|c|c|c|c|c|}
\hline \multirow{2}{*}{ Group } & \multirow{2}{*}{$\begin{array}{c}\text { Mean } \\
\text { Age }\end{array}$} & \multirow{2}{*}{ M } & \multirow{2}{*}{ F } & \multicolumn{3}{|c|}{ Mean Scores } \\
\hline & & & & Plaque & Gingivitis & Periodontal \\
\hline I & 42.8 & 23 & 16 & $1.192 \pm 0.0379 *$ & $1.165 \pm 0.0443 *$ & $4.142 \pm 0.0615 \%$ \\
\hline II & 44.4 & 22 & 17 & $1.145 \pm 0.0397 *$ & $1.173 \pm 0.0560 *$ & $4.125 \pm 0.0855 *$ \\
\hline \multicolumn{7}{|c|}{ Five Days After Prophylaxis } \\
\hline \multirow{2}{*}{ Group } & \multirow{2}{*}{$\begin{array}{l}\text { Mean } \\
\text { Age }\end{array}$} & \multirow{2}{*}{$M$} & \multirow{2}{*}{$F$} & \multicolumn{3}{|c|}{ Mean Scores } \\
\hline & & & & Plaque & Gingivitis & Periodontal \\
\hline I & 42.8 & 23 & 16 & $0.705 \pm 0.0402 *$ & $0.449 \pm 0.0461 *$ & $4.044 \pm 0.0672 *$ \\
\hline II & 44.4 & 22 & 17 & $0.733 \pm 0.0425 \%$ & $0.468 \pm 0.0498 \%$ & $4.060 \pm 0.0826 \%$ \\
\hline
\end{tabular}

*Standard Error

TABle 1

systematic coverage of the entire mouth was stressed.

Each patient was instructed to use any adjunctive method to brushing which he was now using, but to use these adjuncts with either brush. No attempt was made to control the number of brushings per day for either brush.

\section{STATISTICAL ANALYSIS OF DATA}

The scores were statistically evaluated to analyze between-group and within-group differences. The means of the plaque, scores of Group I and II were used as an indication of the effectiveness for preventing or removing the dental plaque from the teeth. The means of the gingivitis and periodontal

COMPARISON OF SCORES WITHIN GROUP I AT 30 AND 60 DAYS (Total Study 120 Days)

\begin{tabular}{|c|c|c|c|c|}
\hline $\begin{array}{c}\text { Tooth Brush } \\
\text { Utilized }\end{array}$ & $\begin{array}{c}\text { Scoring } \\
\text { Time } \\
\text { In Days }\end{array}$ & Plaque & Gingivitis & Periodontal \\
\cline { 3 - 5 } $\begin{array}{c}\text { Standard } \\
\text { Design }\end{array}$ & 30 & $1.069 \pm 0.0224 *$ & $0.915 \pm 0.0445 *$ & $3.979 \pm 0.0944 *$ \\
\hline $\begin{array}{c}\text { Standard } \\
\text { Design }\end{array}$ & 60 & $1.163 \pm 0.0253 *$ & $1.073 \pm 0.0438 *$ & $4.020 \pm 0.0923 *$ \\
\hline \multicolumn{5}{|c|}{ Prophylaxis Rendered and Tooth Brushes Switched } \\
\hline Electric & $\begin{array}{c}30 \\
(90 * *)\end{array}$ & $1.054 \pm 0.0172 *$ & $0.750 \pm 0.0362 *$ & $3.924 \pm 0.1092 *$ \\
\hline Electric & $\begin{array}{c}60 \\
(120 * *)\end{array}$ & $1.161 \pm 0.0251 *$ & $0.984 \pm 0.0462 *$ & $3.921 \pm 0.1033 *$ \\
\hline
\end{tabular}

*Standard Error

**: Time From Beginning of the Study 
COMPARISON OF SCORES WITHIN GROUP II AT 30 AND 60 DAYS

(Total Study 120 Days)

\begin{tabular}{|c|c|c|c|c|}
\hline $\begin{array}{c}\text { Tooth Brush } \\
\text { Utilized }\end{array}$ & $\begin{array}{c}\text { Scoring } \\
\text { Time } \\
\text { In Days }\end{array}$ & \multicolumn{3}{|c|}{ Me a n S cores } \\
\cline { 3 - 5 } Electric & 30 & $1.020 \pm 0.0397 *$ & $0.993 \pm 0.0454 *$ & $3.962 \pm 0.1218 *$ \\
\hline Eiectric & 60 & $1.138 \pm 0.0320 *$ & $1.104 \pm 0.0402 *$ & $3.999 \pm 0.1168 *$ \\
\hline \multicolumn{5}{|c|}{ Prophylaxis Rendered and Tooth Brushes Switched } \\
\hline $\begin{array}{c}\text { Standard } \\
\text { Design }\end{array}$ & $\begin{array}{c}30 \\
(90 * *)\end{array}$ & $1.073 \pm 0.0302 *$ & $0.628 \pm 0.0469 *$ & $3.942 \pm 0.1304 *$ \\
\hline $\begin{array}{c}\text { Standard } \\
\text { Design }\end{array}$ & $\begin{array}{c}60 \\
(120 * *)\end{array}$ & $1.138 \pm 0.0396 *$ & $0.891 \pm 0.0542 *$ & $3.985 \pm 0.1252 *$ \\
\hline
\end{tabular}

*Standard Error

***Time From Beginning of the Study

TABLE 3

scores were used as an indication of the effect on the periodontium. A comparison of the mean plaque, gingivitis, and periodontal scores between or within the groups was used to show relative effectiveness of the electric and the hand toothbrush. The Student's "t" test was used to analyze the between-group and within-group differences.

\section{RESULTS}

In Group I, there was no statistical difference $(\mathrm{P}=.01)$ between the mean scores of 30 and 90 days or 60 and 120 days in either plaque or periodontal scores (Table 2 ). Thus in Group I after 30 and 60 days, there was no difference between the mean scores of the patients on the standard design toothbrush and the Broxodent electric toothbrush.

In Group I, there was a statistical difference $(P=.01)$ in gingivitis scores when comparing the gingivitis scores of patients having used the Lactona for 30 days and the electric toothbrush for 30 days. However, when comparing the gingivitis scores at the end of 60 days, there was no statistical difference at the 0.01 level of confidence (Table 2).

Both the mean plaque and the mean gingivitis scores of patients in Group I slowly increased from the 30 to 60 day scoring periods. Thus, plaque and gingivitis slowly increased after the initial prophylaxis regardless of the type of brush used. The mean plaque and gingivitis scores at the end of 30 days approximated the scores reached after 60 days on either brush. Also, after the patients in Group I had been on either brush for 60 days, the plaque and gingivitis scores were approximately the same as the scores prior to prophylaxis.

There was no statiscal difference $(P=$ .01 ) in the periodontal scores in Group I after the patients had been on either brush for 30 and 60 days. There was no significant reduction in periodontal scores at the end of 120 days in Group I.

In Group II, there was no statistical difference $(\mathrm{P}=.01)$ between the mean scores of 30 and 90 days or 60 and 120 days in either plaque or periodontal scores (Table $3)$. Thus in Group II after 30 and 60 days, there was no difference between the mean scores of the patients on the Broxodent electric toothbrush and the standard design toothbrush.

In Group II, there was a statistical difference $(P=.01)$ in gingivitis scores when 


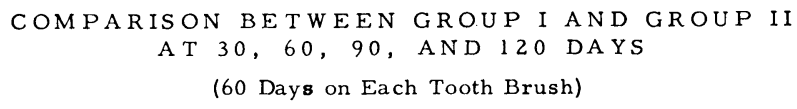

\begin{tabular}{|c|l|c|c|c|c|}
\hline Group & \multirow{2}{*}{$\begin{array}{c}\text { Tooth Brush } \\
\text { Utilized }\end{array}$} & $\begin{array}{c}\text { Time } \\
\text { in } \\
\text { Days }\end{array}$ & Plaque & Gingivitis & Periodontal \\
\hline I & Standard Design & 30 & $1.069 \pm 0.0224 *$ & $0.915 \pm 0.0445 *$ & $3.979 \pm 0.0944 *$ \\
\hline II & Electric & 30 & $1.020 \pm 0.0397 *$ & $0.993 \pm 0.0454 *$ & $3.962 \pm 0.1218 *$ \\
\hline I & Standard Design & 60 & $1.163 \pm 0.0253 *$ & $1.073 \pm 0.0438 *$ & $4.020 \pm 0.0923 *$ \\
\hline II & Electric & 60 & $1.138 \pm 0.0320 *$ & $1.104 \pm 0.0402 *$ & $3.999 \pm 0.1168 *$ \\
\hline & Prophylaxis Rendered and & Tooth Brushes Switched \\
\hline I & Electric & $\begin{array}{c}30 \\
(90 * *)\end{array}$ & $1.054 \pm 0.0172 *$ & $0.750 \pm 0.0362 *$ & $3.924 \pm 0.1092 *$ \\
\hline II & Standard Design & $\begin{array}{c}30 \\
(90 * *)\end{array}$ & $1.073 \pm 0.0302 *$ & $0.628 \pm 0.0469 *$ & $3.942 \pm 0.1304 *$ \\
\hline I & Electric & $\begin{array}{c}60 \\
(120 * *)\end{array}$ & $1.161 \pm 0.0251 *$ & $0.984 \pm 0.0462 *$ & $3.921 \pm 0.1033 *$ \\
\hline II & Standard Design & $(120 * *)$ & $1.138 \pm 0.0396 *$ & $0.891 \pm 0.0542 *$ & $3.985 \pm 0.1252 *$ \\
\hline
\end{tabular}

Standard Error

$*$ Time From Beginning of the Study

TABLE 4

comparing the gingivitis scores of patients having used the electric toothbrush for 30 and 60 days and the standard design brush for 30 and 60 days (Table 3 ).

Both the mean plaque and mean gingivitis scores of patients in Group II slowly increased from the 30 to 60 day scoring periods. The plaque and gingivitis scores slowly increased after the initial prophylaxis regardless of the type of brush used. The mean plaque and gingivitis scores at the end of 30 days approximated the scores reached after 60 days on either brush. Also, after the patients in Group II had been on either brush for 60 days, the plaque and gingivitis scores were approximately the same as the scores prior to prophylaxis.

There was no statistical difference ( $\mathrm{P}$ .01 ) in the periodontal scores in Group II after the patients had been on either brush for 30 and 60 days. There was no significant reduction in periodontal scores at the end of 120 days in Group II.

There was no significant statistical difference $(P=.01)$ between the mean plaque, gingivitis, and periodontal scores of Group I and Group II at 30, 60, 90, and 120 days (Table 4).

\section{DISCUSSION}

Analysis of differences between or within the two comparable groups showed no statistically significant differences of the two brushes in plaque, gingivitis, and periodontal scores. These results agree with the findings of Chilton and El-Kashlan, ${ }^{15}$ and Chilton, Di Dio, and Rothner ${ }^{16}$ who studied the effect of the same electric toothbrush on plaque and gingivitis, and with Oldenburg and Wells ${ }^{9}$ who studied its effect on oral debris.

The novelty effect of the electric toothbrush was quite apparent in the present study. Most of the patients were very enthusiastic about the electric toothbrush at the beginning of the study, but were much less enthusiastic at the end of the study. The novelty effect occurred in both groups of the present study, and it is possible that the mean scores obtained following use of the electric brush were affected; however, the novelty effect probably was 
of no significance because of apparent decay of the effect over the long period of the study. This finding was apparent in Berman's study ${ }^{13}$ of 61 recall patients in a periodontal practice. Approximately onethird of the patients in his study returned to their old way of brushing before completion of the study. Many of the short term studies have not considered this aspect of electric toothbrushes. The novelty effect of an electric brush also must be considered in any evaluation of plaque removal based on a single brushing test.

Some difficulty was experienced when Group II, which started on the electric toothbrush, was switched to the standard design toothbrush. Some of these patients commented they suffered toothbrush lacerations when returning to a hard, natural bristle toothbrush. However, because of the period of time which elapsed before these patients were scored after switching brushes, there was no apparent effect on the mean scores of Group II.

Although there was a reduction in gingivitis scores during the second half of this study, the reduction was never as great as that present five days after prophylaxis. Even so, there was a gradual increase in gingivitis scores from the 90 day to the 120 day scoring period. The reduction in gingivitis was probably related to repeated prophylaxis and the introduction of new brushes.

Although there was no statistically significant difference in plaque scores after 120 days on either brush, there was a statistically significant reduction in gingivitis scores after 120 days. This finding suggests that in patients with reasonably good home care, there is no correlation between the inherent accumulative plaque plateau and gingivitis. However, in the absence of reasonably good home care, accumulations of plaque and the character of the plaque could be altered and be related to gingivitis. The periodic prophylaxis with the removal of calculus appeared to be more significant in the reduction of gingivitis than the degree of plaque present or the use of any specific brush by the patients in this study. The inverse relationship between plaque and gingivitis also was noted by Hoover and Robinson ${ }^{3}$ in a study of dental students. In studies by O'Leary, Shannon, and Prigmore ${ }^{34}$ and Greene and Vermillion $^{35}$ the correlation coefficient between periodontal disease and calculus was reasonably high and significantly different from 0 . No correlation specifically, between plaque and gingivitis, was mentioned in these studies; however, in the study by O'Leary, et al. the mean periodontal disease index was 2.86. This mean score indicates that on the average, subjects in that study did not have a crevicular depth extending apically to the cemento-enamel junction. In Ramfjord's index ${ }^{21}$ the gingivitis score is used instead of the periodontal score when the crevicular depth does not extend apical to the cemento-enamel junction. This may be the reason that Hoover and Robinson concluded that O'Leary's study showed no correlation between plaque and gingivitis.

In the present study there was no significant difference in the periodontal scores from the initial examination to the final scoring. Thus periodontal scores do not follow the pattern of change of gingivitis scores and suggests the absence of correlation between periodontal scores and gingivitis scores; however, the period of time of this study does not warrant these conclusions. The absence of any changes in the periodontal score after repeated prophylaxis suggests that the period of time was not sufficient for any changes to occur, at least with the brushes and method of brushing used. However, these findings indicate that marked changes in the periodontium following the use of the electric toothbrush do not occur in short periods of time as suggested by some investigators.

A large number of patients in this study had gingival recession with cemental exposure and loss of interproximal tissue. With exposure of the cemental and interproximal surfaces of the tooth the procedures of oral hygiene are more demanding 
than under normal conditions. Thus, under the conditions of this study the demands of oral hygiene were more extensive than in those studies using young adult dental students with relatively normal periodontium. This consideration could explain the absence of a marked reduction in plaque and gingivitis found by other investigators. However, the scores resulting from the use of patients with gingival recession do not indicate that the findings of this study could not be applicable to patients with a normal gingiva. Therefore, it is logical to assume that with the roll-method of brushing with a hand brush or with an electric toothbrush that the effectiveness of either brush would be no better for patients with a normal gingiva than those patients with gingival recession.

Some women and older patients experienced some difficulty in stopping the electric toothbrush tested, since some degree of strength is necessary to press the two buttons which act as a brake on the shaft of the electric brush. Since women and older patients were equally distributed in both groups, the difficulty experienced with the switch could be expected to have affected the scores of both groups equally. This type of switch has been changed on newer models of this toothbrush.

Failure to score calculus during the study period introduced an inherent weakness in this study. Although the initial score represents in part the effect of the accumulation of calculus on the teeth, it is reasonable to assume that the effect of calculus was equally distributed in both groups. The rate of calculus formation was not determined; however, the lack of a direct evaluation of the rate of calculus formation does not directly affect the results of this study.

After a short period of time the bristles of the electric brush became splayed as noted by other investigators. ${ }^{1,} 18$ Although this probably indicated the patients were using too much pressure with the electric brush, it might also indicate the brushes were receiving extensive use. Even though splaying of the bristles of the brush could be suggestive of improper use of the brush, it is doubtful whether patients under other circumstances with even less instructions in their use will do differently. In order to limit the possible effect of reduced effectiveness of splayed brushes, additional brushes were made available to the patients where splaying was a consideration.

Five to seven days after prophylaxis the average plaque score was approximately 0.705 for Group I and 0.722 for Group II. By the end of 30 days the plaque score was 1.069 for Group I and 1.020 for Group II. These plaque scores at 30 days were statistically equivalent to the initial plaque scores prior to prophylaxis. The plaque scores at the end of 60 days were also statistically equivalent to the initial scores. These findings suggest that plaque builds up rather rapidly during the first week and reaches a plateau by 30 days. Studies on toothbrushing shorter than 30 days might show an apparent absolute reduction in plaque following a prophylaxis where in effect the evaluation of plaque had been assessed at a period of time when plaque was accumulating. To assume there was an absolute reduction in plaque in a study of less than 30 days would lead to erroneous conclusions unless the rate of plaque formation is known and considered.

Most of the patients in this study had not received a prophylaxis any less than four months prior to the initial scoring. Thus, it appears that the accumulation of plaque present at the initial scoring represents a plateau of accumulated plaque which is related to individual differences in plaque formation in routine home care. Since these patients had been on periodic maintenance and periodic prophylaxis four months prior to the beginning of this study, periodic prophylaxis also must be considered as related to accumulated plaque plateau.

\section{SUMMARY}

A study of the effect of an electric toothbrush on dental plaque, gingivitis, and periodontal scores was made with 78 individuals over a period of four months. Two 
comparable groups of 39 patients were formed on the basis of plaque scores, rate of plaque formation, gingivitis scores, periodontal scores, age, and sex. One group received an electric toothbrush (Broxodent) and the other a standard toothbrush (Lactona). Plaque, gingivitis, and periodontal scores were obtained at 30, 60, 90, and 120 days. The type of brush used in each group was changed after 60 days. A statistical evaluation of scores indicates there is no significant difference in the effect of the two brushes on plaque, gingivitis, and periodontal scores.

\section{CONCLUSIONS}

1. The electric toothbrush and the standard hand toothbrush used in this test were equally effective in preventing or removing dental plaque and both have an equal effect on gingivitis and periodontal scores.

2. There appears to be an inherent plateau of accumulated plaque on the teeth that is related to individual differences in plaque formation, routine home care, and periodic prophylaxis. This plateau is reached in about 30 days following prophylaxis and approximates the plaque present prior to prophylaxis.

3. Neither the electric toothbrush nor the standard hand brush tested specifically prevented plaque on the teeth from reaching an inherent accumulated plateau.

4. Periodontal scores do not significantly change in short periods of time (less than four months) in patients with reasonably good oral hygiene.

\section{BIBLIOGRAPHY}

1. Birch, R. H. and Mumford, J. M. Electric toothbrushing. Dent. Pract., 13:182-86, Jan. 1963.

2. Chilton, N. W. and Kutscher, A. H. Use of an electric toothbrush by a severely handicapped (arthrogryposis) man-a case report. N. J. S. Dent. Soc. J., 33:20-21, Sept. 1961 .

3. Hoover, D. R. and Robinson, H. B. G. Effect of automatic and hand toothbrushing on gingivitis. Am. Dent. A. J., 65:361-67, Sept. 1962.

4. Sopakar, P. N. and Quigley, G. A. A comparative study of gingivitis with manual and power brushing. J. Dent. Res. I.A.D.R. Program and $\mathrm{\Lambda b}$ stracts of Papers. Mar. 1963.

5. Phaneuf, E. A., et al. Automatic toothbrush: a new reciprocating action. Am. Dent. A. J., 65:1225 , July, 1962.

6. Terry, Ira and Harrington, J. H. Abrasion tests on acrylic. Am. Dent. A. J., 65:377, Sept. 1962.

7. Vibra Dent toothbrushes charged misbranded, unsafe. Am. Dent. A. J., 64:866, June, 1962.

8. Toto, P. D. The clinical usefulness of the Broxodent automatic action toothbrush in home and institutional oral hygiene. Pub. Health Dent., 22: 15-22, Spring Issue, 1962.

9. Oldenburg, T. R. and Wells, H. B. The effectiveness of the electric toothbrush in reducing oral debris in handicapped children. J. Dent. Res., I.A.D.R. Program and Abstracts of Papers, Mar. 1963.

10. Kelner, M. The use of an electric powered toothbrush in the home dental care of handicapped children. Pa. Dent. J., 28:3-8, Nov. 1961.

11. Lefkowitz, William and Robinson, H. B. G. Effectiveness of automatic and hand brushes in removing dental plaque and debris. Am. Dent. A. J., 65:351-61, Sept. 1962.

12. Savastano, Gennaro. Evaluation of an automatic action toothbrush in children. Dent. Digest, 68:19-21, Jan. 1962 .

13. Berman, C. L., et al. Observations of the effects of an electric toothbrush. J. Periodont., 195198, Apr. 1962.

14. Toto, P. D. and Farchione, Alfred. Clinical evaluation of an electrically powered toothbrush in home periodontal therapy. J. Periodont., 32:249-54, July, 1961.

15. Chilton, N. W. and El-Kashlan, Khalil. Studies in the design and analysis of dental experiments. IV. A modified analysis of variance in a clinical toothbrushing experiment. J. Dent. Res., 41:84-95, Jan.-Feb. 1962.

16. Chilton, N. W., Di Dio, A., and Rothner, J. T. Comparison of the effectiveness of an electric and a standard toothbrush in normal individuals. Am. Dent. A. J., 64:777-82, June, 1962.

17. Collins, E. S. and Curtis, G. H. A preliminary report on the automatic action electric toothbrush. South. Calif. S. Dent. A. J., 24:214-17, July, 1961.

18. Cross, W. G., Forrest, J. O., and Wade, A. B. A comparative study of tooth cleansing using conventional and electrically operated toothbrushes. Brit. Dent. J., 113 (1):19-22, July 3, 1962.

19. Quigley, G. A., and Hein, H. W. Comparative cleansing efficiency of manual and power brushing. Am. Dent. A. J., 65:26-29, July, 1962.

20. Kapur, Krishan and Shklar, Gerald. Effects of a power device for oral physiotherapy on the mucosa of the edentulous ridge. J. Pros. Dent., 12: 762-69, July-Aug. 1962. 
21. Ramfjord, Sigurd. Indices for prevalence and incidence of periodontal disease. J. Periodont., 30: 51-9, Jan. 1959.

22. Shick, R. A. and Ash, M. M. Evaluation of the vertical method of toothbrushing. J. Periodont. 32:346-53, Oct. 1961 .

23. Jamison, H. C. Prevalence and severity of periodontal disease in a sample of a population. University of Michigan, School of Public Health. 1960. $\mathrm{xi}+153$ p. Typed thesis.

24. Ramfjord, Sigurd. The periodontal status of boys, 11-17 years old in Bombay, India. J. Periodont., 32:237-48, July, 1961.

25. Bass, C. C. The optimum characteristics of toothbrushes for personal hygiene. Dent. Items Interest, 70:697-718, July, 1948.

26. Bunting, R. W. Oral hygiene, 3rd ed., Philadelphia, Lea and Febiger, 1957. 334 p. (27-8).

27. Charters, W. J. Home care of the mouth: I. proper home care of the mouth. J. Periodont., 19:136-7, Oct. 1948.

28. Hard, Dorothy G. Dental scientist suggests watching mirror while brushing teeth. Ark. Dent. J., 23:18, Sept. 1952 .

29. Curtis, G. H., et al. Clinical study of the effectiveness of the roll and Charter's method of brushing teeth. J. Periodont., 28:277-80, Oct. 1957.

30. Hine, M. K. The use of the toothbrush in the treatment of periodontitis. Am. Dent. A. J., $41: 158-68,1950$.

31. Hine, M. K. The toothbrush. Internat. Dent. J., 6:15-25, Mar. 1956.

32. Hirschfeld, Isador. The toothbrush: its use and abuse. Brooklyn, Dent. Items of Interest Pub. Co., 1939XVI + $591 \mathrm{p}$.

33. Hirschfeld, Isador. The why and how of toothbrushing. Am. Dent. A. J., 32:80-5, Jan. 1, 1945.

34. O’Leary, T. J., Shannon, I. L., and Prigmore, J. R. Clinical and systemic findings in periodontal disease. J. Periodont., 33:243-51, July, 1962.

35. Green, J. C., and Vermillion, J. R. Oral hygiene index: a method for classifying oral hygiene status. Am. Dent. A. J., 61:172, Aug. 1960.

\section{Announcement ...}

\section{AMERICAN CLEFT PALATE ASSOCIATION}

The Twenty-second Annual Meeting of the American Cleft Palate Association will be held at the Statler Hilton Hotel in Los Angeles, California, on Thursday, Friday, and Saturday, April 30 and May 1 and 2, 1964. The 1964 program will include outstanding papers, table clinics and exhibits, a luncheon, and special features now being planned by the Program Committee. Members of the Association do not pay a convention fee. Student guests are admitted without charge, with proper identification; non-student guests pay a fee of $\$ 3.00$. The Statler-Hilton Hotel will furnish housing for students consisting of a four bed dormitory room at a special rate. The Hotel is in the downtown area of Los Angeles and 80 per cent of the scientific meetings will be held there. The preliminary program will be published in March, 1964. 